\title{
Clipboard
}

\section{Order in stress - Lessons from the inanimate world}

Life can be considered as an outcome of complex molecular processes which result in the existence of a thermodynamically ordered, far from equilibrium state. The maintenance of this order in living systems is energy-dependent and follows the basic laws of physics and chemistry. However, at times of stress, when the energy pool of a cell goes down, maintaining dynamic order becomes difficult. In such a situation, how can the equilibrium imposed by the second law of thermodynamics be avoided? Can there be order in stress (Minsky et al 2002)?

Highly ordered intracellular assemblies have been found in cells subjected to prolonged stress. In this process, termed as biocrystallization, vital components of the cell, like DNA, are physically sequestered and protected. These intracellular assemblies are thermodynamically stable and are independent of energy, reminiscent of ordered states in the inanimate world such as crystals and liquid crystals, both of which correspond to free energy minima of the system.

The first report of biocrystallization of DNA appeared in 1999 (Wolf et al 1999). It was shown that DNA, along with a stress-induced protein (Dps) of Escherichia coli, can form biocrystals both in vitro and in vivo (figure 1). The functional relevance of this observation was shown two years later (Frenkiel-Krispin et al 2001) when it was found that DNA-Dps biocrystallization was a growth phasedependent phenomenon, and was associated with prolonged starvation (2 day-old culture). Overexpression of Dps in the log phase did not result in its co-crystallization with DNA. Divalent cations were shown to trigger the process. Elevated concentrations of $\mathrm{Mg}^{2+}$ ions not only prevented co-crystallization, but also caused the pre-existing ordered complexes to fall apart, showing the reversible nature of this biological process. The protection of DNA in a DNA-Dps co-crystal was dependent on $\mathrm{Mg}^{2+}$ ions in vitro. It was proposed that extracellular divalent cations provided an on-off signal for intracellular DNA-Dps co-crystallization; the cations were known to be depleted upon prolonged starvation. The presence of Dps homologs like ferritin (Grant et al 1998) in other organisms suggests that this might be a conserved protective mechanism. Frenkiel-Krispin et al (2001) also showed that an alternative mechanism of DNA protection existed in $d p s^{-}$mutants. Upon prolonged stress (6 day-old culture), this mutant strain of E. coli showed DNA arranged in an ordered liquid-crystal phase known as the cholesteric phase (figure 2). Pure DNA is known to be in a highly ordered state, namely a

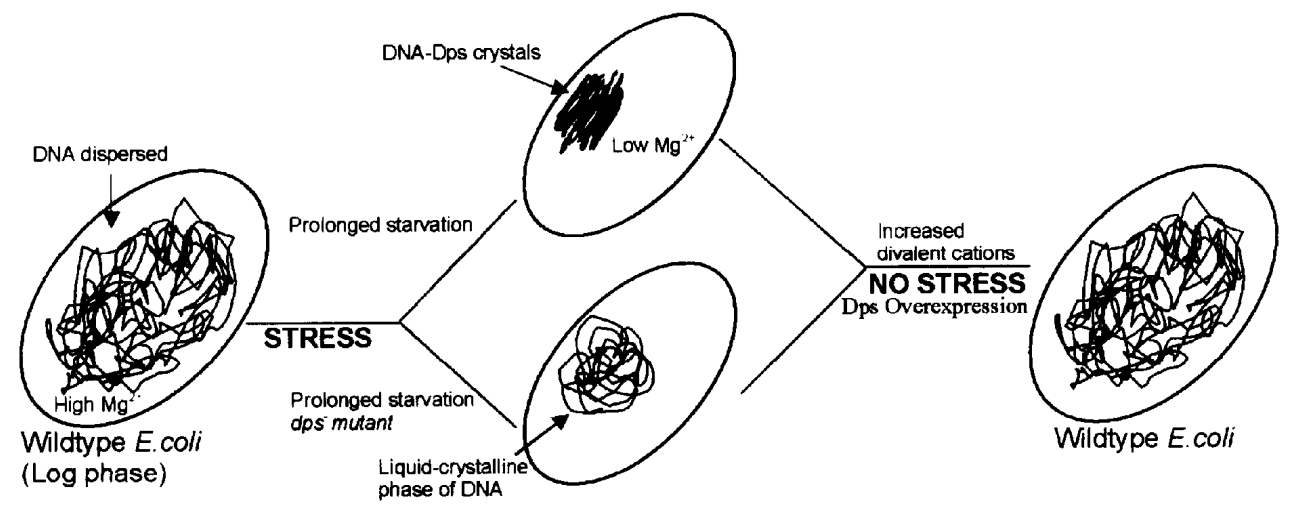

Figure 1. Model for DNA-Dps cocrystallization. 
liquid-crystalline phase, at very high concentrations (Livolant 1991; Livolant and Leforestier 1996; Reich et al 1994). The liquid crystalline phase is known to reduce the accessibility of DNA to irradiation, radicals and nucleases (Newton et al 1996).

In mid-log phase $E$. coli cells treated with nalidixic acid (which effects double-strand breaks by stalling the activity of DNA gyrase), ordered RecA-DNA assemblies are seen (Levin-Zaidman et al 2000). The periodic order exhibited by RecA-DNA assemblies is high enough to allow crystallographic averaging $(47 \AA$ ). It has been proposed that ordered assemblies accelerate RecA-mediated homologous repairing of DNA double-strand breaks by restricting the diffusion of DNA and reducing the dimensionality of the process (Adam and Delbruck 1968). It is hypothesized that RecA searches for the homologous template through one-dimensional motion that is enforced by parallel organization of the RecA-DNA assembly. Therefore, cocrystallization could protect DNA from further damage (i) by limiting its accessibility and (ii) by helping RecA to correct the damage more efficiently by reducing its search area for a homologous DNA template. Upon unstressed incubation, the E. coli cells revert back to the wild-type phenotype and the ordered assemblies disappear rapidly.

These reports suggest that bacteria survive harsh environmental conditions by sequestering DNA using minimum energy and subsequently reverse this process on return to favourable conditions. The DNA molecule is known to be less active (no duplication and little transcription) in the condensed form of chromatin. This is in accordance with the fact that compaction of DNA is in response to stress, which might lead to a reduction in the energy pool of the cell. Hence the cell minimizes the use of energy by reducing energy-consuming processes. The B form of DNA is maintained in the cholesteric liquid-crystalline phase in vitro as well as in vivo (Livolant 1991).

Are there examples of organisms that encounter harsh environmental conditions often and use this protection strategy over much of their lifetime? In a recent report, a similar protection mechanism was shown to be operating continuously in Deinococcus radiodurans (Levin-Zaidman et al 2003). This Gram-positive non-sporulating bacterium survives very high doses of ionizing radiations $(\sim 15000$ Grays); much lesser doses ( 10 Grays) are lethal to other organisms. The resistance to ionizing radiation is not attributed to highly efficient repair enzymes because the organism possesses a 'typical' bacterial complement of these enzymes. However, D. radiodurans has DNA arranged in an extremely ordered manner, shaped like a toroid (figure 3). Interestingly, recA-deficient D. radiodurans cells are capable of correcting a significant amount of damage. It was hypothesized that a non-RecA-dependent homologous recombination repair pathway is functional in the organism, aided by the precise alignment of templates in the toroidal form of DNA (Englander et al 2004). The presence of an X family DNA polymerase, PolX $\mathrm{X}_{D r}$ being associated with the repair of double-stranded DNA breaks, suggests that non-RecA-dependent repair corrects lesions while being aided by the compact DNA structure (Englander et al 2004; Lecointe et al 2004).

Making spores is a strategy employed by various organisms to tide over unfavourable conditions. A toroidal DNA form was seen in B. megaterium spores (Ragkousi et al 2000). The DNA-SspC complex
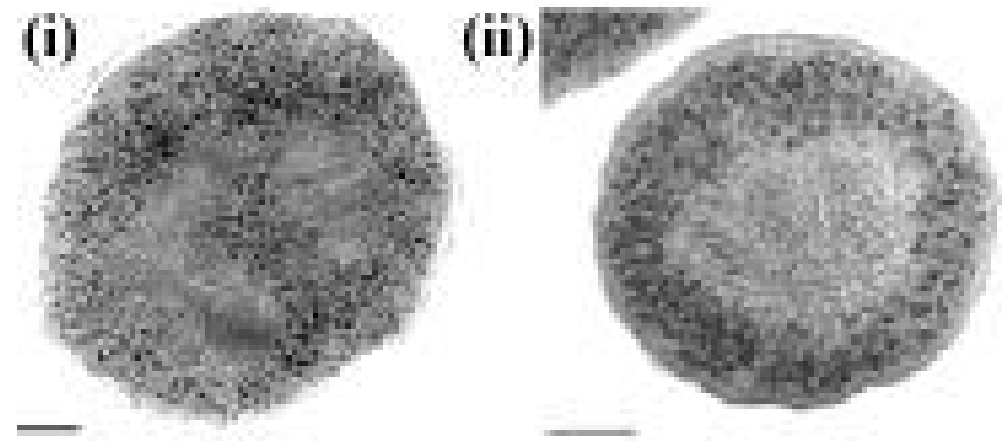

Figure 2. In situ DNA-Dps assemblies. (i) Crystalline assemblies in starved (48 h) wildtype E. coli. (ii) Liquid-crystalline phase of DNA seen in $d p s^{-}$mutant of $E$. coli after prolonged incubation (6 days). (Courtesy Minsky A). 


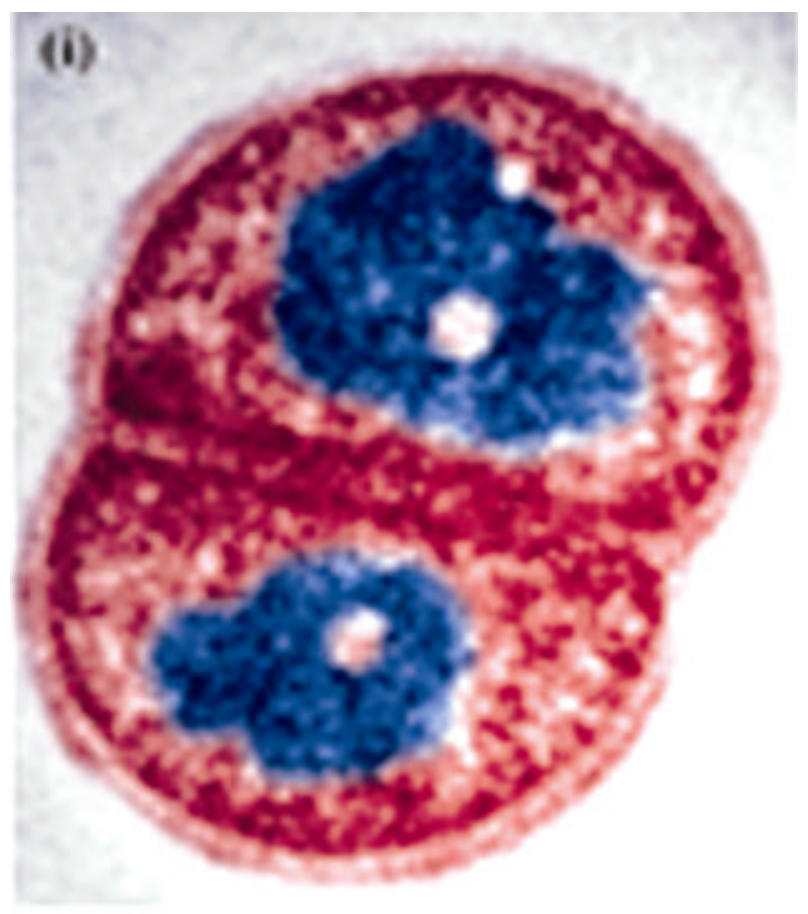

(ii)

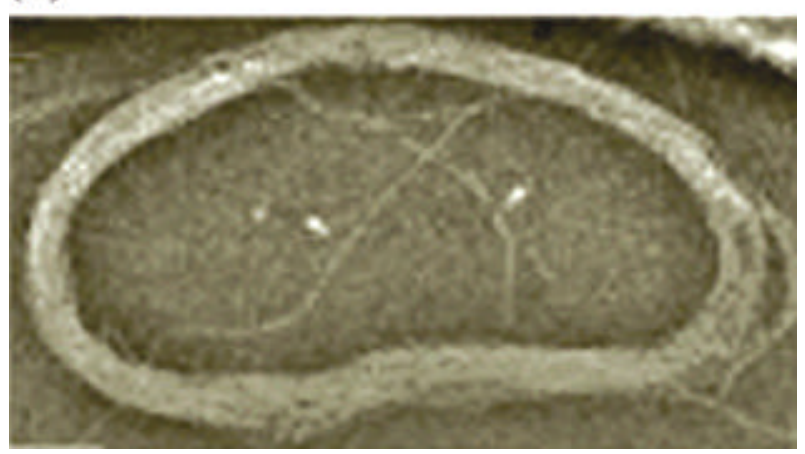

Figure 3. Toroidal DNA shape. (i) Colour-processed transmission electron micrograph of a cryofixed $D$. radiopugnans cell, depicting the toroid-like organization of its chromatin (blue). (ii) DNA-SspC complex seen in the form of a toroid. (Courtesy Minsky A).

( $\alpha / \beta$ type small, acid-soluble spore proteins) is said to assume a toroidal shape in vitro (figure 3); this, along with the in vivo data, could explain the robust nature of spores (Englander et al 2004; Frenkiel-Krispin et al 2004). Also, the nucleic acids in bacteriophage T7 has been shown to be tightly packaged in toroids (Cerritelli et al 1997).

Apart from DNA, ribosome crystals have been reported earlier. Large, crystalline assemblies of ribosomes are formed in mouse and lizard oocytes during winter hibernation (Barbieri et al 1995). The Hirano-bodies found in brain cells of a patient with Alzheimer's disease were found to be ribosome crystals (O'Brien et al 1980). These reports need to be further confirmed in order to conclusively prove that the compaction of vital cellular components is common (not only specific to DNA), and to make a strong case for biocrystallization as a general survival strategy used by different organisms. The adaptive value of such a mechanism is evident; given that crystallization is an inherent property of matter, it would be worth exploring whether natural selection has a role to play in the phenomenon. 
The crystalline form, which was considered not long ago a property of the inanimate world, now seems to be an important and sometimes essential part of the animate world.

\section{Acknowledgments}

I thank Abraham Minsky for valuable suggestions and permission to use the pictures.

\section{References}

Adam G and Delbruck M 1968 Reduction of dimensionality in biological diffusion processes: Structural chemistry and molecular biology (eds) R Rich and N Davidson (San Francisco: Freeman)

Barbieri M, Vittone A and Maraldi N M 1995 Cell stress and ribosome crystallization; J. Submicrosc. Cytol. Pathol. 27 199-207

Cerritelli M E, Cheng N, Rosenberg A H, McPherson C E, Booy F P and Steven A C 1997 Encapsidated conformation of bacteriophage T7 DNA; Cell 91 271-280

Englander J, Klein E, Brumfeld V, Sharma A K, Doherty A J and Minsky A 2004 DNA Toroids: Framework for DNA Repair in Deinococcus radiodurans and in Germinating Bacterial Spores; J. Bacteriol. 186 5973-5977

Frenkiel-Krispin D, Levin-Zaidman S, Shimoni E, Wolf S G, Wachtel E J, Arad T, Finkel S E, Kolter R and Minsky A 2001 Regulated phase transitions of bacterial chromatin: a non-enzymatic pathway for generic DNA protection; EMBO J. 20 1184-1191

Frenkiel-Krispin D, SacK R, Englander J, Shimoni E, Eisenstein M, Bullitt E, Horowitz-Sherer R, Hayes C S, Setlow P, Minsky A and Wolf S G 2004 Structure of the DNA-SspC complex: Implications for DNA packaging, protection, and repair in bacteiral spores; J. Bacteriol. 186 3525-3530

Grant R A, Filman D J, Finkel S E, Kolter R and Hogle J M 1998 The crystal structure of Dps, a ferritin homolog that binds and protects DNA; Nature Struct. Biol. 5 294-303

Lecointe F, Shevelev I V, Bailone A, Sommer S and Hubscher U 2004 Involvement of an X family DNA polymerase in double-stranded break repair in the radioresistant organism Deinococcus radiodurans; Mol. Microbiol. 53 1721-1730

Levin-Zaidman S, Frenkiel-Krispin D, Shimoni E, Sabanay I, Wolf S G and Minsky A 2000 Ordered intracellular RecA-DNA assemblies: a potential site of in vivo RecA-mediated activities; Proc. Natl. Acad. Sci. USA 97 6791-6796

Levin-Zaidman S, Englander J, Shimoni E, Sharma A K, Minton K W and Minsky A 2003 Ring-like Structure of the Deinococcus radiodurans Genome: A Key to Radioresistance?; Science 299 254-256

Livolant F 1991 Ordered phases of DNA in vivo and in vitro; Physica A 176 117-137

Livolant F and Leforestier A 1996 Condensed phases of DNA: structure and phase transitions; Prog. Polym. Sci. 21 1115-1164

Minsky A, Shimoni E and Frenkiel-Krispin D 2002 Stress, order and survival; Nature Rev. Mol. Cell Biol. 3 5060

Newton G L, Aguilera J A, Ward J F and Fahey R C 1996 Polyamine-induced compaction and aggregation of DNA -a major factor in radioprotection of chromatin under physiological conditions; Radiat. Res. 145 776780

O'Brien L, Shelley K, Towfighi J and McPherson A 1980 Crystalline ribosomes are present in brains from senile humans; Proc. Natl. Acad. Sci. USA 77 2260-2264

Ragkousi K, Cowan A E, Ross M A and Setlow P 2000 Analysis of nucleoid morphology during germination and outgrowth of spores of Bacillus species; J. Bacteriol. $1825556-5562$

Reich Z, Wachtel E J and Minsky A 1994 Liquid-crystalline mesophases of plasmid DNA in bacteria; Science 264 1460-1463

Wolf S G, Frenkiel-Krispin D, Arad T, Finkel S E, Kolter R and Minsky A 1999 DNA protection by stressinduced biocrystallization; Nature (London) 400 83-85

AASHIQ HUSSAIN KACHROO

Department of Molecular Reproduction,

Development and Genetics,

Indian Institute of Science,

Bangalore 560 012, India

(Email,aashic@mrdg.iisc.ernet.in)

ePublication: 29 November 2004 